\title{
Interpretation of the metabolic effects of trauma and sepsis
}

\author{
H B STONER
}

From the Department of Surgery, Hope Hospital, Salford

SUMMARY John Hunter suggested that the body's responses to injury were defensive and had survival value. Now, many years later, we are still uncertain about this. Although our appreciation of the endocrine and metabolic responses to injury, both physical and bacterial, has increased enormously our knowledge of these events, particularly at a molecular level, is still very incomplete. Patterns have been identified, however, in the sphere of energy metabolism, and this provides a basis for interpreting at least some of the biochemical responses to injury. The views developed support the idea that the responses are defensive-initially against the impact of the injury and then to meet the demands of the new "organ" which the wounds or septic focus seem to have added to the body. A reason for wanting to interpret these responses is to improve patient care. Current interpretations at least help to clarify our view of what is happening in the injured or septic patient and sometimes indicate lines of treatment. Nevertheless, many serious problems, particularly changes in protein metabolism, remain to be solved before we can advise on the metabolic care of patients at all stages from accident to recovery.

By interpreting the data acquired during the examination and investigation of a patient the pathologist can make an important contribution to treatment. This interpretative role is not confined to diagnosis from surgical biopsy specimens or routine blood and urine samples. It can include the interpretation of the metabolic changes which follow trauma and accompany sepsis. These metabolic effects have been studied increasingly during the past 50 years, and there is now a considerable amount of information about the state of patients in these conditions. We should go beyond the mere description of these responses and attempt to say what they mean. Even to use the word "responses" carries interpretative overtones, and one soon begins to seek the object of these metabolic events. To do so inevitably introduces a teleological approach to the problem but we need not be ashamed of this. Teleology was first introduced into this subject by Hunter, ${ }^{1}$ and $\mathrm{Krebs}^{2}$ has adequately defended its use for this purpose. Indeed, the furtherance of pathology would often be difficult without it.

Up till now the interpretation of the metabolic response to trauma has depended on two ideas. The first, proposed by Hunter, ${ }^{1}$ was that all these changes were defensive, and the second, proposed later by Cuthbertson, ${ }^{3}$ was that the response could be divided into two linked parts, an early and a late, which he called the "ebb" and "flow" phases. There is little difficulty in accepting the division of the metabolic effects of trauma into two parts, an early group of changes precipitated by the injury and lasting about a day, and a second, later group of quite different changes which reach their peak during the second week after the injury. Can these two groups of effects really be linked together; can they always be described as defensive; and while "flow" may be a useful description for the hypermetabolism and catabolism of the second phase, is "ebb", which implies depression of metabolism, such a good word for the early changes in all species? During the past few years similarities between the metabolic responses to trauma and sepsis have become apparent. ${ }^{4}$ Sepsis leads to a state that combines many of the changes of the ebb and flow phases of trauma. What light can this throw on our understanding of these events, where similar changes are produced by apparently dissimilar stimuli?

Trauma and sepsis affect all tissues and metabolic pathways to some extent. Our knowledge of these changes is insufficient to be able to interpret them all; but enough is now known to attempt the interpretation of the overall changes in energy metabolism 
in ways that will be helpful for the patient's treatment.

\section{The "ebb" phase}

\section{THE DEFENCE REACTION}

Physiologists, starting with WB Cannon, have established the existence of a defensive physiological response triggered by the special senses which, through its effects on the cardiovascular and endocrine systems, equips the subject to meet an aggressive challenge. ${ }^{5}$ Many parts of the brain participate in this reaction, but the key is the hypothalamus which generates the efferent effector impulses for this coordinated response. It does this through its many neural connections and endocrine neurones which have humoral effects on the pituitary and elsewhere. ${ }^{6}$

\section{Neuroendocrine response to trauma}

If injury occurs any input from the special senses will be supplemented or reinforced by the afferent stimulation provided by nociceptive stimuli from the injured tissues, and by changes in blood volume and pressure due to haemorrhage and exudation into the damaged area. The size of the response will depend on the severity of the injury, and it will reach its maximum rapidly-in minutes rather than hours. Some of the neuroendocrine changes can be very large; the concentration of circulating catecholamines can increase up to 1000 times, ${ }^{78}$ and that of vasopressin by over a 100 -fold. ${ }^{9}$ In some cases the relation to severity is not just a positive direct one over the whole range. The plasma adrenocorticotrophic hormone (ACTH) concentration plateaus at a less than maximal value, when the severity of the injury exceeds that classified as moderate. ${ }^{10}$ Although on average these adrenocorticotrophic hormone concentrations would be judged sufficient to give a maximal stimulus to the adrenal cortex, the corresponding plasma cortisol concentrations are not always maximal and are poorly correlated with adrenocorticotrophic hormone. The relation between the plasma cortisol concentration and the severity of the injury is complex. ${ }^{1011}$ The highest concentrations are found after moderate trauma, while after very severe injuries the plasma concentrations are lower, both in absolute terms and in relation to those of adrenocorticotrophic hormone. There are some additional secondary endocrine changes, for the increased catecholamine activity leads to glucagon secretion ${ }^{1213}$ and the hyperadrenalinaemia inhibits the secretion of insulin. ${ }^{1415}$ Both these factors ${ }^{913}$ activate the reninangiotensin system and hence aldosterone secretion.

These are the most important endocrine changes from the point of view of the response to injury. Several other hormones are secreted at this time, $\beta$-lipotrophic hormone, prolactin, and pituitary growth hormone, but their roles are obscure.
Energy metabolism

These neuroendocrine responses are sufficiently large to produce metabolic effects, the most important being related to the energy metabolism of the body. The secretion of adrenaline, vasopressin, and glucagon and the activation of the sympathetic nerves lead to the breakdown of glycogen in liver and muscle but not in brain or heart. ${ }^{16}$ The relative importance of these factors varies with species and organ: in rats adrenaline is responsible for the breakdown of glycogen in muscle but not in liver ${ }^{16}$; in man adrenaline seems to be important, judging by the good relation between the concentrations of glucose and adrenaline in the plasma. ${ }^{14}$ In the liver glycogen yields glucose, while in muscle the product which is transported to the liver to be converted to glucose in the Cori cycle is almost entirely lactate. The net result is the transference of glucose from the glycogen stores to the extracellular space.

Increased sympathetic activity also leads to the hydrolysis of the triacylglycerol stored in the fat depots. Provided that an adequate supply of the carrier albumin reaches the adipocytes this will raise the concentration of the non-esterified fatty acids in the plasma. After severe trauma the passage of nonesterified fatty acids from depot to circulation may be hindered by hypovolaemia and vasoconstriction so that the plasma concentration can be quite low. ${ }^{111718}$ The other product of lipolysisglycerol-will diffuse out more easily and be converted to glucose in the liver.

These metabolic changes affecting the energy stores would seem a fitting accompaniment to the physiological reactions needed for "fight or flight". An easily available energy source such as glucose should be beneficial at that stage. It can be shown in animal experiments that the availability of energy stores and the responses of the pituitary, adrenal medulla, and cortex are all needed in the further defence against injury, for the removal or inactivation of any one of them will aggravate the effects of trauma and shorten the survival time after fatal injuries. ${ }^{1920}$ Once an injury has occurred however, particularly if it is severe, another problem is introduced. The animal cannot simply continue to behave normally, for there will be a period when it is difficult to forage for food and water. Further steps must be taken if the animal is to preserve some of its energy stores and hydration during this period, and there is evidence that appropriate measures are incorporated in the early response.

The early secretion of vasopressin will favour water retention; and the breakdown of glycogen will liberate its bound water which will help to preserve the blood volume. ${ }^{21}$ Some think that the hyperglycaemia also assists hydration by exerting an osmotic effect in 
the tissues. ${ }^{22}$ Activation of the renin-angiotensin system will also have a role here, as will the adrenal cortex which can also, in some cases, be concerned in the beneficial movement of fluid from tissue to vessel. ${ }^{23}{ }^{24}$ The main problem is to preserve, as far as possible, the glucose exposed in the extracellular space. The normal carbohydrate stores are insufficient to maintain the body for very long, and this glucose will be rapidly frittered away unless the body can turn to the more abundant fat for fuel: there is evidence that this is what happens. At this stage after the injury oxygen transport to the tissues is adequate and the cells will accept whatever fuel is available, but adequate use of glucose may be impaired in insulin sensitive tissues. ${ }^{40}$ Inhibition of insulin secretion by adrenaline is partially responsible but there is also evidence for a post-receptor insulin resistance in which both adrenaline and glucocorticoids may play a part. ${ }^{25-28}$ The net effect of these changes will be to reduce the availability of glucose for oxidation and hold it in the extracellular space. Evidence for this was seen when indirect calorimetry was carried out on injured patients shortly after arrival in an accident and emergency department. ${ }^{29}$ While those with minor or moderately severe injuries showed a respiratory exchange ratio (RQ) that is commonly found in controls on a mixed diet $(0 \cdot 86)$, those with severe injuries had a low RQ (0.78), indicating a switch to fat as fuel. These patients may be oxidising no more glucose than that required in the brain.

There is still a great deal to be discovered about these metabolic events at a molecular level ${ }^{3031}$ and also about the neural and endocrine mechanisms which generate them. ${ }^{632}$ Nevertheless, an overall pattern of reaction has emerged, at least in regard to energy metabolism. In the early part of the response to injury this has a clearly defensive role.

THERAPEUTIC IMPLICATIONS OF THE EBB PHASE Is the natural response adequate or should we try to modulate the neuroendocrine response of the ebb phase in an effort to "improve" it? It might be argued that with modern anaesthesia and surgery a defensive response of this type is no longer required. Alternatively, it could be said that if the response is "good" it should be increased. There is little support for this latter proposition. Additional exogenous glucose would not be used and no benefit has been derived from giving large doses of glucocorticoid. ${ }^{33} 34$ If there is evidence of endocrine failure steps should be taken to replace the missing factor, but otherwise there is no call for additional hormones.

While general anaesthesia, as usually given, has little effect on the neuroendocrine response to trauma this response can be reduced in several ways $^{35}$ - namely, by interrupting the afferent path- ways with regional anaesthesia; by inhibiting the central mechanisms with "high dose" opiate anaesthesia or the efferent pathway by high spinal anaesthesia. When this was done in patients undergoing elective surgery of minor or moderate severity, their clinical course seemed to be unaffected. It is not known what effect these procedures would have on patients suffering severe trauma, either accidental or operative. Critically ill patients do need to have adrenal cortical response. ${ }^{3637}$ Furthermore, the natural response to trauma occurs so rapidly that it would be difficult to carry out such techniques before the response was fully fledged. One is left with the impression that this neuroendocrine mechanism is so complex and finely tuned that by itself it will perform optimally in the defence of the injured patient. The advice for this stage should echo that of Larrey ${ }^{38}$ and Trueta $^{39}$-namely, early decisive measures to reduce the size of the injury (by replacement of lost fluid, reduction of nociceptive stimuli, treatment of fractures, removal of non-recoverable tissue) and thus the need for the response.

\section{Homoeostatic reflexes}

While there seems to be no reason to interfere with the metabolic events of the ebb phase, there is another aspect which might require attention. The afferent nociceptive stimuli arising from the damaged tissue and ascending in the spinothalamic tracts not only stimulate the neuroendocrine response but also inhibit thermoregulation and the reflex homoeostasis of the cardiovascular system both in man and laboratory animals. ${ }^{40}$

Although the central effects of trauma on thermoregulation are probably the same in large and small mammals, the manifestations of this disturbance differ because of the different ways in which they control their body temperatures. Large mammals vary the rate of heat loss, while small mammals depend mainly on changes in the rate of heat production, particularly by non-shivering thermogenesis. Thus it is the failure of the heat production mechanism to respond to ambient temperatures below the thermoneutral zone which causes the depression of oxidative metabolism in injured rats under these environmental conditions and gives such a clear identification of the ebb phase as a phase of decreased metabolism in that species. ${ }^{41}$ This is not seen in the larger mammals ( $>10 \mathrm{~kg}$ ), in which non-shivering thermogenesis is less important ${ }^{42}$; and oxygen consumption can be very variable in a recently injured person. ${ }^{43}$

While the changes in thermoregulation may have a defensive role ${ }^{44}$ this cannot be said of the effect of the nociceptive stimuli on the cardiovascular reflexes-or at least it is not obvious. ${ }^{40}$ Straightforward loss of fluid, as in moderately severe haemorrhage, leads to 
an increase in the efficiency of these reflexes, but this is overridden by the inhibitory effect of the nociceptive stimuli. In clinical terms this means that the effects of an injury that combines loss of fluid and tissue damage are greater than would be expected from the loss of fluid alone. This represents a modification of the long held view that the effects of trauma can be explained by the amount of fluid lost. It also means that the elimination of nociceptive afferent impulses would be beneficial, although the best way of doing that is not yet known.

\section{ETHANOL}

So many accidental injuries have been preceded by the consumption of ethanol that it is important to be able to take this into account when interpreting the metabolic changes in injured patients. The consumption of ethanol does not change the catecholamine or adrenal cortical responses to the injury ${ }^{4113}$ but it does change some of their metabolic effects. Ethanol decreases the redox state of the liver and inhibits gluconeogenesis. ${ }^{45}$ This results in a lower glucose and a higher lactate concentration in the plasma than would otherwise by expected from the severity of the injury. ${ }^{11}$ In patients without ethanol, positive relations have been found between the plasma glucose and lactate concentrations and the severity of the injuries. Parallel relations have been found in patients who have consumed ethanol. These differences must be taken into account if the plasma lactate concentration is being used to monitor the patient's progress. Despite these effects there is little evidence $^{46}$ that ethanol affects the outcome through its metabolic effects. The dangers come from aspiration of vomit, unconsciousness, and the greater difficulty in diagnosing the injuries of the intoxicated patient.

\section{Necrobiosis-irreversible shock}

If the prime aim of the physiological responses of the ebb phase is to maintain adequate oxygen transport to the tissues, particularly in those organs on which life depends, then it must be admitted that in some cases they fail. When oxygen transport falls below a critical level, the ebb phase will cease and the injured patient or animal will pass into a state of necrobiosis or shock which will end in death unless very vigorous measures are taken, and even then these may not prevent fatility. This change has sometimes been described as the step from a physiological to a pathological response to injury. ${ }^{47}$ It can arise when the injury is overwhelming as with torrential haemorrhage, when there has been delay in reaching hospital, or when the patient has been inadequately supported during the ebb phase - for example, failure to stop bleeding. Nowadays, in an urban environment with good hospital facilities few patients should reach this stage.

The metabolic events at this time are dominated by the failure of oxygen transport and are no longer part of a defence reaction. Through lack of oxygen the redox state of the tissues falls, the lactate:pyruvate and 3-hydroxybutyrate:acetoacetate ratios rise, and lactate accumulates to cause a metabolic acidosis. The changes in plasma lactate concentration can be used to monitor this condition. ${ }^{4849}$ The impairment of oxidative metabolism will lead to failure of the membrane pumps, which in turn will lead to the intracellular accumulation of sodium and calcium and loss of potassium. All those functions of the cell which depend on oxygen will become increasingly deranged. ${ }^{30} 31$

These events should be avoided at all costs by the early, vigorous treatment of those aspects of the patient's injuries which may give rise to them. There is no substitute for the early arrest of haemorrhage, replacement of lost fluid, and the reduction of fractures and other measures that will lessen nociceptive stimulation.

\section{The flow phase}

In man the metabolic events of the flow phase reach their climax during the second week after the injury and are usually complete after about three weeks. The typical features of this stage are a raised energy expenditure and body temperature, with increased nitrogen excretion.

Although the changes of the flow phase are positively related to the severity of the injuries, as will be shown later, this association is probably an indirect one, and these changes should not be regarded as a continuation of those of the ebb phase. The neuroendocrine response of the ebb phase persists for some 24 hours, after which, in the absence of further direct stimulus, it rapidly declines. Within a few days of the injury hormone and substrate concentrations in the plasma approximate to normal. ${ }^{11-14}$ There are exceptions. After burns ${ }^{50}$ the plasma noradrenaline concentration may remain raised until skin healing is well advanced. In old age plasma cortisol concentrations remain high for long periods after moderate injuries despite low plasma adrenocorticotrophic hormone values. ${ }^{51}$ The main endocrine feature of the flow phase relates to insulin. Within a few days of the injury the plasma insulin concentration rises out of proportion to the plasma glucose concentration, to reach a maximum during the second week after the injury. ${ }^{11125253}$ It has been shown by the euglycaemic clamp technique that these patients show insulin resistance (Henderson A, Frank KN, Little 
RA (personal communication). ${ }^{54}$ This insulin resistance is not confined to carbohydrate metabolism; it may account for the increased output of creatine. ${ }^{55}$ There is also a surprising positive relation between the urinary nitrogen loss and the plasma insulin concentration, so that insulin resistance may extend to protein metabolism. ${ }^{1252}$

When considering the increase in urinary nitrogen excretion after injury, it is important to distinguish the later increases in output from those which are often found during the first three days. During that initial period the excess of nitrogenous compounds may include quite large amounts of 3-methylhistidine and creatinine, derived from the breakdown of muscle directly damaged by the injury. ${ }^{56}$

The urinary abnormalities accompanying the flow phase proper last about three weeks in patients who recover without complications. When these occur the changes can persist for much longer. The best chemical monitor is the change in creatine excretion. Normally very little creatine is lost in the urine, but a few days after an injury its excretion starts to increase, reaching a peak during the second week and then slowly returning to normal. ${ }^{57}$ Of the compounds in the urine, creatine shows the best correlation with the severity of the injury as measured by the injury severity score. ${ }^{58}$ While some of the early output can come from damaged muscle the main loss is from muscle not damaged in the accident, and this is a clear indication that the biochemical disturbances of the flow phase extend far beyond the damaged tissues.

The increased excretion of nitrogen in the urine was originally thought to be due to the breakdown of muscle protein, explaining the obvious loss of muscle mass. This was disputed, and it was thought that the extra nitrogen was due to inhibition of protein synthesis with breakdown of the amino acids that would have been used for that purpose. In fact, the situation is more complex as the type of mechanism operating seems to depend on the severity of the injury.

When the injury is slight, or moderate muscle protein synthesis and breakdown are both depressed and as the effect on synthesis is the greater, there is a net loss of muscle mass. ${ }^{59}$ Recent work by Rennie et al ${ }^{60}$ suggests that this could be related to the central role of glutamine in muscle protein metabolism. Glutamine is the most abundant of the free intracellular amino acids in muscle. Its uptake by muscle depends on a special transport system linked to that of sodium so that its concentration ratio across the membrane depends on the reciprocal of the sodium gradient. Its intracellular concentration has a pronounced effect on the rate of muscle protein synthesis. This transport system is very sensitive to changes in the hormone and electrolyte milieu-that is, to the changes which accompany trauma and sepsis: an increase in intra- cellular sodium will lead to a loss of glutamine and reduced protein synthesis. ${ }^{60}$ Striking falls in the free glutamine concentration of muscle are found after accidental and operative trauma and in sepsis, ${ }^{61-63}$ although the changes are not directly related to the severity of the insult as measured by usual scoring systems. One could speculate, therefore, that the changes in muscle protein metabolism, after lesser degrees of trauma, reflect changes in the function of the muscle cell membranes. Of the glutamine lost from the muscle cells some may be used by lymphocytes ${ }^{64}$ but most is probably removed by the liver, broken down, and excreted as urea.

After serious injuries the situation is quite different. In these patients muscle protein synthesis and breakdown are both increased, with the major change affecting the breakdown. ${ }^{59}$ Unlike the previous group these patients can excrete large amounts of 3-methylhistidine. ${ }^{56}$ This unuseable amino acid formed in the degradation of actomyosin is, in this instance, an indicator of muscle protein breakdown. The reason for the different responses in the two situations is not known. The free glutamine concentration will fall in these patients too. Although interleukin-1 itself does not seem to be responsible for the loss of muscle protein, ${ }^{65}$ polypeptides which may be related to it such as catabolin, cachectin, and proteolysis inducing factor might have a dominant role in promoting muscle protein breakdown. This has been suggested but not yet proved. ${ }^{596667}$ The problems outlined in this and the preceding paragraph provide the research worker in this subject with his or her most serious challenge.

It must be emphasised that protein metabolism does not respond in the same way in all parts of the body. While there is loss of muscle protein, there is at the same time an increase in the export of certain proteins from the liver, with an increase in the plasma concentrations of acute phase reactants. ${ }^{68}$ On the other hand, the main export protein of the liver, albumin, decreases in the plasma, reaching a nadir about five days after the injury. The main factor in this case is change in the distribution of albumin rather than any change in its metabolism. ${ }^{68}$

The increased production of acute phase reactants that occurs after quite minor injuries has been thought to be due to interleukin-1 formed by activated leucocytes in the damaged tissue. ${ }^{69}$ This matter, too, is rapidly becoming more complicated as a whole family of polypeptides of the interleukin type is uncovered. It will be some time before it is finally decided which of these compounds (such as hepatocyte stimulating factor) is responsible and what the precise nature of their role is. Endogenous leucocyte pyrogen is a member of this group and thought to be the cause of fever in these patients. 
These events are accompanied by a moderate increase in energy expenditure. This increase does not exceed about $30 \%$, except after large burns ( $>50 \%$ ) when the increase may be up to $100 \%$. There are obvious cardiovascular and respiratory limitations to the increases which can occur in the metabolic rate. ${ }^{43}$ The caloric contribution of protein to the increase does not exceed $20 \%$. The extra fuel is derived from fat and carbohydrate, both of which are oxidised at an increased rate during this period despite the insulin resistance. ${ }^{53}$

Thinking on the reasons for these changes in energy expenditure has been dominated by the results of work on burns. Before we consider these studies, however, and before we discuss the aims of the flow phase, if indeed there are any, it will be useful to describe some of the metabolic events associated with sepsis due to pyogenic bacteria.

\section{Sepsis}

Serious sepsis due to pyogenic bacteria can arise in many ways. Typical causes are the infection of wounds. the perforation of a hollow abdominal viscus, leakage from an intestinal anastomosis, and other intra-abdominal conditions, with localised or generalised peritonitis leading to the development of subphrenic, pelvic, or other abscesses. The infection is usually mixed and the metabolic sequelae seem to depend on the presence of sepsis rather than on the nature of the infecting organism. We have recently come to realise that the metabolic effects of sepsis resemble those of trauma. Despite episodes of septicaemia and septic shock the time course is usually slower and there is not usually anything resembling the sudden stimulus of an accidental injury; nevertheless, from the point of view of energy and intermediary metabolism one sees a mixture of ebb and flow phase changes, and if the patient dies the terminal changes are those of the necrobiotic phase after trauma. ${ }^{4}$

\section{ENERGY METABOLISM}

Patients with serious sepsis exhibit a hypermetabolic, catabolic state. The greatest increases in energy expenditure are seen when sepsis occurs in a previously healthy person. So many of these patients have been ill for long periods with conditions such as Crohn's disease that they are already severely depleted before the septic episode. In such patients energy expenditure may seem quite low (1500-1800 $\mathrm{kcal} / \mathrm{day}$ ), although it represents a considerable increase for them. The fuel for this energy expenditure is increasingly derived from fat; the more severe the sepsis the less carbohydrate is oxidised..$^{70-72}$ The increase in energy expenditure cannot be simply explained by any fever present.

Protein metabolism is affected. In the plasma the concentrations of the acute phase reactants are increased while that of albumin is usually low. There is loss of muscle protein with wasting and an increased urinary output of nitrogen and, in severe cases, of 3-methylhistidine.

The plasma substrate concentrations vary considerably in these patients. ${ }^{71}$ This may reflect the ways in which these patients are treated, for many are given parenteral nutrition. The turnover of plasma nonesterified fatty acids is increased and greater amounts are oxidised than would be expected from the plasma concentrations. ${ }^{7374}$ Because the use of glucose is inhibited, a hyperosmolar state can develop if excessive amounts of glucose are given that lead to its accumulation in the extracellular space. The plasma concentrations of noradrenaline, adrenaline, and cortisol are moderately raised, depending on the severity of the sepsis. ${ }^{71} 75$ In some patients with very severe, usually fatal, sepsis low plasma cortisol concentrations are found, along with a poor response to exogenous adrenocorticotrophic hormone. ${ }^{76}$ In these patients there is evidence of adrenal cortical failure, but usually adequate amounts of glucocorticoid are produced and secreted by the gland. Adrenaline concentrations are not often high enough to inhibit insulin secretion. Plasma insulin concentrations in sepsis are variable, but when challenged by a glucose infusion the pancreas will respond with a normal biphasic insulin response. Nevertheless, the effects of this insulin are reduced and these patients show clear signs of insulin resistance in the hyperglycaemic glucose clamp test. ${ }^{75}$ Glucose uptake, measured by arteriovenous differences across a muscle bed, is reduced. These tests point to a major change in glucose storage capacity. The fate of large amounts of glucose given to septic patients over long periods, however, is not so clear. No more is really known about the mechanisms of these changes at a molecular level than is the case in trauma.

There are obvious implications in these findings for the metabolic care of septic patients, particularly regarding the use of fat as an energy source in parenteral nutrition. ${ }^{707177}$ The positive relation between the severity of the metabolic disturbance and that of the sepsis is another similarity with trauma and calls for urgent surgery to reduce the sepsis-by draining abscesses etc - if necessary by exposing the whole of the infected area as in laparotomy. Antibiotics are of limited value in the absence of septicaemia.

Why should sepsis and recovery from traumatic injury be accompanied by this very similar pattern of metabolic events, an outstanding feature of which is the increase in energy expenditure? To answer this 
question we must return to the study of burns.

\section{The wound as an organ}

From the study of large unilateral full thickness burns of the leg and from his animal experiments Wilmore ${ }^{78}$ developed the concept of the wound as a separate organ added to the body by the injury. This new organ is formed by the thick granulating surface of the burn. It has a large supply of blood traversing a profusion of new blood vessels not under nervous control and contains enormous numbers of leucocytes, macrophages, fibroblasts and regenerating epithelial cells. Like any other organ it both takes from and gives to the rest of the body. Because of its large vascularity and blood flow, cardiac output has to be increased to meet its needs. Cardiac output may be more than doubled in these patients. The wound consumes large amounts of glucose. This is mainly broken down to lactate which returns to the body to be resynthesised into glucose in the Cori cycle of the liver. Aerobic glycolysis in the cells of the wound that are probably insulin independent produces most of the adenosine triphosphate (ATP) required by the wound. Oxygen, however, is used by the wound, mainly for fat and amino acid oxidation and in the synthesis of collagen. Glutamine may be an important substrate for oxidation in wounds. Amino acids will be extracted from the plasma for protein synthesis, and adequate amounts of ascorbic acid and trace elements will also be needed. These changes will reach a maximum after about two weeks, coinciding with the peak of the flow phase.

What influence do these events have on the energy metabolism of the burned patient? The highest rates of oxygen consumption are found when burns are treated by exposure and a great deal of the increased oxidation is to make good the latent heat of evaporation for the large evaporative water loss from the surface of the burn. This will occur even if an eschar is present as the eschar is freely permeable to water. Henane $^{79}$ has tried to draw up a balance sheet for patients with more than $50 \%$ burns. Although he found that the distribution between dry (radiation and convection) and wet (evaporative) heat loss in his patients was very variable he was able to show that about $70 \%$ of the increase in energy expenditure was used to meet these thermal requirements. This left $30 \%$ unaccounted for, but there are a number of claimants. Interleukin-1 produced by the burn will cause fever, and there is a $10 \%$ increase in oxygen consumption for every ${ }^{\circ} \mathrm{C}$ rise in body temperature. Extra oxygen will be needed for the increase in cardiac output, for the hepatic gluconeogenesis (Cori cycle), and to meet the specific oxygen requirements of the wound. At present we lack data to be able to complete the balance sheet but it seems likely that these features would make good the deficit.

Can these ideas, developed from the study of burns, be applied to other forms of injury and sepsis? There is little specific about burns from this point of view. Any exposed granulating surface, as in a laparostomy or in a large degloved area of a limb, will increase the evaporative loss from the body and so increase oxygen consumption. It has already been emphasised that the large increases in metabolic rate are only seen when there are exposed areas of this kind. With closed injuries such as multiple long bone fractures and with deep seated abscesses the increases are more modest. These injuries also create areas of granulation tissue that may be extensive and which can be regarded as a new organ in the body. As in burns this new tissue will require an increased cardiac output to maintain the circulation through it, will consume glucose, produce lactate, use oxygen and raise body temperature (via interleukin-1). These changes will normally reach a peak about two weeks after the injury and the size of the body's response to them - that is, the flow phase in the case of trauma - will be related to the amount of this new tissue formed. It is easy to see, therefore, why the flow phase after trauma and the responses to sepsis are both similar and related to severity.

If this view of events is correct the flow phase response to trauma and sepsis is determined by the size of the local reaction. In trauma there will be a positive relation between the flow phase and the initial injury, because the size of the local reaction is determined by the injury. If this is removed, by amputation of a damaged limb, the flow phase response is much less than would otherwise be expected. ${ }^{57}$ With this pathogenesis it is not surprising that flow phase changes seem unrelated to the neuroendocrine responses of the ebb phase and have not been reproduced by the infusion of counter-regulatory hormones as in the "triple hormone" experiments of Wilmore and others. ${ }^{8081}$ It also explains why the response to major elective surgery is often so smallthe amount of granulation tissue in the healing area is small. Similarly, it is reasonable that the hypermetabolic response to infection sites should depend on the pyogenic potential of the bacteria. Specific organisms, such as Clostridia with their range of toxic enzymes or Escherichia coli which will add a lipopolysaccharide endotoxin, may introduce specific effects, but these will be additional to the basic response.

Although progress has been made in interpreting these changes in energy metabolism as a response to the mass of new tissue added to the body, the accompanying changes in protein metabolism are more difficult to explain. Changes occur both in synthesis and breakdown, but the mechanisms entailed are not 
clear. The only hormone that seems to participate is insulin but eicosanoids may also be implicated. ${ }^{12}$ Although interleukin-1 is thought to trigger some of the protein changes, it seems unlikely to have a role in the loss of muscle mass. ${ }^{65}$ The possibility that other peptides, perhaps derived from interleukin-1, are responsible for this, lacks confirmation. Without knowing the mechanism in changes in protein metabolism it is difficult to allot them any purpose but two possibilities should be considered. Is the demand for glucose by the wound so great that glucogenic amino acids must be mobilised from the tissues to increase the amount of glucose available, or does the wound require particular rare amino acids which can only be obtained in sufficient amount by breaking down large amounts of tissue? Answers to these questions are not yet available, and studies on the changes in the composition of skeletal muscle which occur at this time have not been very helpful, except insofar as they have highlighted the fall in glutamine content. For the clinician the loss of muscle mass and function and accompanying debilitation cause concern but until these questions can be answered scientific advice on this aspect of patient care will be missing. It is difficult to increase the size of the muscles by parenteral nutrition; any increase in body weight is mostly due to water and fat.

There is, however, one important consequence to interpreting the flow phase as the response to the presence of a new organ. If this response is an attempt by the body to provide for the needs of this new organ, any attempt to curtail it, without at the same time reducing the size of the organ, would be counterproductive. The aim of treatment should be to support the response, and the best ways of doing that will become clear when we learn more about the mechanisms entailed. Can the flow phase then be looked on as a defensive mechanism? In a sense yes, although not in quite the same way as the ebb phase. The flow phase is probably the obligatory response to the demands of the new tissue in the wound, burn, abscess wall, etc. It will remain necessary as long as that demand is maintained and there is no way in which it can be avoided. If the demands of the wound cannot be met the patient will succumb. The equation here is between the size of the demands and the metabolic, cardiovascular, and respiratory reserves of the body. As our current ways of supporting patients in these states are still empirical one must emphasise the need for vigorous treatment of the causative lesions. This is specially obvious in the case of sepsis.

\section{Other biochemical consequences of trauma and sepsis}

It has only been possible to deal here with the effects on energy metabolism and the associated changes in hormones and substrates. This is only part of the response to trauma and sepsis, as almost every organ and biochemical pathway in the body is affected, sometimes to a major degree. Similar space would be needed for a full discussion of the activation of the enzyme cascades of the plasma and their effects on clotting ${ }^{82}$ and the complement system, ${ }^{83}$ to say nothing of the immunological disturbances. The mechanisms of these changes have been investigated in considerable detail and are beginning to be understood. Their interpretation in terms of survival value is more difficult.

Hunter seems to have viewed the whole response to trauma as a defensive one. Some of the changes in the systems just mentioned illustrate the difficulty of sustaining that simple view. While fibrin formation is an essential part of haemostasis, this is only beneficial if it can be contained. If the process spreads to cause disseminated intravascular coagulation the result may be fatal. This is an example of the two edged nature of many of the responses to trauma and sepsis; up to a point the responses are defensive and beneficial, beyond that point they can lead to disaster. It seems that faced with attack the body often gambles. Much more research is needed to find ways of estimating the odds in a particular patient, often a question of the size of that patient's reserves, and to continue to develop treatment that will increase the chances of survival.

\section{Conclusion}

Two questions were posed in the Introductionnamely, how the two stages in the response to trauma, the ebb and flow phases, are linked together, and whether these and the similar response to sepsis are defensive reactions. Evidence has been presented, from the sphere of energy metabolism, that leads to the conclusion that the two phases of the response to trauma are only indirectly linked, as the first is a reaction to the injury itself and is completed well before the second (which seems to be a response to the local tissue reactions around the wounds) is fully established. The response to sepsis is similar because it too is provoked by the new tissue in the septic lesion.

These responses are defensive but not in the same way in each case. The early ebb phase is part of a wider neuroendocrine defence mechanism aimed initially at mobilising the energy stores of the body for "fight or flight" and then, if injury occurs, conserving these stores until recovery can occur. The later flow phase and the similar response to sepsis are determined by the addition of a new "organ" to the body. They are the inevitable consequence of the body's attempt to "defend" the new situation and provide for the needs of the new organ. 
In the Introduction I said that the interpretation of pathological events should lead to improvements in patient care. Some therapeutic implications of the interpretation of the metabolic effects of trauma and sepsis have been indicated. The idea that today's patient, with all the facilities of modern hospital medicine at his or her disposal, no longer requires these responses developed in earlier times is probably not well founded. The neuroendocrine response calls for little interference on our part. It is in full swing before the patient reaches hospital, and it seems, with few exceptions, to cope well with the early problems. Treatment at this stage should be to reduce, or at least limit, the size of the injuries.

As the later responses seem to be obligatory ones to meet the demands of the new "wound-organ" it would be unwise to try to prevent them. Attempts should be made to hasten the resolution of the lesion by draining abscesses, for example, otherwise these reactions should be supported. Unfortunately, the best way of doing this will not be clear until we have a much better understanding of the biological purpose of some of these reactions, particularly those affecting protein metabolism.

This paper extends and develops views expressed in the Roy Cameron lecture I gave in 1985.

\section{References}

1 Hunter J. A treatise on the blood, inflammation and gunshot wounds. London: Nicol, 1794.

2 Krebs HA. Excursion into the borderland between biochemistry and philosophy. Bulletin of the John Hopkins Hospital 1954;95:45-51.

3 Cuthbertson DP. Post-shock metabolic response. Lancet 1942;i:433-7.

4 Stoner HB. Metabolism after trauma and in sepsis. Circulation Shock 1986;19:75-87.

5 Folkow B, Neil E. Circulation. Oxford: Oxford University Press, 1971.

6 Buckingham JC. Hypothalamo-pituitary responses to trauma. $\mathrm{Br}$ Med Bull 1985;41:203-11.

7 Little RA, Frayn KN, Randall PE, et al. Plasma catecholamines in patients with acute myocardial infarction and in cardiac arrest. $Q J$ Med 1985;54:133-40.

8 Little RA, Frayn KN, Randall PE, Stoner HB, Maycock PF. Plasma catecholamine concentrations in acute states of stress and trauma. Archives of Emergency Medicine 1985;2:46-7.

9 LeQuesne LP, Cochrane JPS, Fieldman NR. Fluid and electrolyte disturbances after trauma: the role of adrenocortical and pituitary hormones. Br Med Bull 1985;41:212-7.

10 Barton RN, Stoner HB, Watson SM. Relationships between plasma cortisol, adrenocorticotrophin and severity of injury in recently injured patients. $J$ Trauma 1987;27:384-92.

11 Stoner HB, Frayn KN, Barton RN, Threlfall CJ, Little RA. The relationship between plasma substrates and hormones and the severity of injury in 277 recently injured patients. Clin Sci 1979;56:563-73.

12 Frayn KN. Hormonal control of metabolism in trauma and sepsis. Clin Endocrinol 1986;24:577-99.

13 Gann DS, Lilly MP. The endocrine response to injury. Prog Crit Care Med 1984;1:15-47.
14 Frayn KN, Little RA, Maycock PF, Stoner HB. The relationship of plasma catecholamines to acute metabolic and hormonal responses to injury in man. Circulation Shock 1985;16:229-40.

15 Frayn KN, Maycock PF, Little RA, Yates DW, Stoner HB. Factors affecting the plasma insulin concentration shortly after accidental injury in man. Archives of Emergency Medicine 1987 (in press).

16 Stoner HB. Studies on the mechanism of shock. The quantitative aspects of glycogen metabolism after limb ischaemia in the rat. Br J Exp Pathol 1958;39:635-51.

17 Stoner HB, Matthews J. Studies on the mechanism of shock. Fat metabolism after injury. Br J Exp Pathol 1967;48:58-65.

18 Kovách AGB, Rosell S, Sándor P, Koltáy E, Kovách E, Tomka N. Blood flow, oxygen consumption, and free fatty acid release in subcutaneous adipose tissue during hemorrhagic shock in cortisol and phenoxybenzamine-treated dogs. Circ Res 1970;26:733-41.

19 Threlfall CJ, Stoner HB. Carbohydrate metabolism in ischaemic shock. Q J Exp Physiol 1954;39:1-9.

20 Stoner HB. The biochemical response to injury. Scientific basis of Medicine annual review. London: Athlone Press, 1961:172-99.

21 Hems DA, Whitton PD. Control of hepatic glycogenolysis. Physiol Rev 1980;60:1-50.

22 Järihult J. Osmolar control of the circulation in hemorrhagic hypotension. An experimental study in the cat. Acta Physiol Scand 1975;(suppl):423.

23 Barton RN, Little RA. Effects of inhibition of adrenal steroidogenesis on compensation of fluid loss and on survival after limb ischaemia in the rat. $J$ Endocrinol 1978;76:293-302.

24 Barton RN, Passingham BJ. Early responses to hemorrhage in the conscious rat: effects of corticosterone. Am J Physiol 1982;243:R416-23.

25 Deibert DC, DeFronzo RA. Epinephrine induced insulin resistance in man. J Clin Invest 1980;65:717-21.

26 Frayn KN. The site of insulin resistance after injury. Endocrino 1977;101:312-4.

27 Barton RN, Passingham BJ. Evidence for a role of gluco corticoids in the development of insulin resistance after ischaemic limb injury in the rat. $J$ Endocrinol 1980;86:363-70:

28 Shamoon H, Soman V, Sherwin RS. The influence of acute physiological increments of cortisol on fuel metabolism and insulin binding to monocytes in normal humans. J Clin Endocrinol Metab 1980;50:495-501.

29 Little RA, Stoner HB, Frayn KN. Substrate oxidation shortly after accidental injury in man. Clin Sci 1981;61:789-91.

30 Heath DF. Subcellular aspects of the responses to trauma. $\mathrm{Br}$ Med Bull 1985;41:240-5.

31 Heath DF. Experimental studies on energy metabolism after injury and during sepsis. In: Little RA, Frayn KN, eds. The scientific basis for the care of the critically ill. Manchester: Man chester University Press, 1986:75-101.

32 Hilton SM, Redfern WS. A search for brain stem cell groups integrating the defence reaction in the rat. $J$ Physiol 1986;378:213-28.

33 Desmonts JM, Pocidalo JJ. Utilisation des corticoides à doses massives dans le choc. Nouv Presse Med 1972;1:2671-6.

34 Fellows IW, Woolfson AMJ. Effects of therapeutic intervention on the metabolic responses to injury. Br Med Bull 1985;41:287-94.

35 Kehlet H, Schulze S. Modification of injury response. In: Little RA, Frayn KN, eds. The scientific basis for the care of the critically ill. Manchester: Manchester University Press, 1986:153-68.

36 Ledingham IMcA, Watt I. Influence of sedation on mortality in critically ill multiple trauma patients. Lancet 1983 ; i:1270.

37 Fellows IW, Bastow MD, Byrne AJ, Allison SP. Adrenocortical suppression in multiply injured patients: a complication of etomidate treatment. Br Med J 1983;287:1835-7.

38 Larrey D. Napoleon's surgeon. London: Heinemann, 1970.

39 Trueta J. War surgery of the extremities in the light of recent 
experience. Lancet 1944 ;i:651-3.

40 Stoner HB. A role for the central nervous system in the response to trauma. In: Little RA, Frayn KN, eds. The scientific basis for the care of the critically ill. Manchester: Manchester University Press, 1986:215-29.

41 Stoner HB. Studies on the mechanism of shock. The impairment of thermoregulation by trauma. $B r \quad J$ Exp Pathol 1969;50:125-38.

42 Heldmaier G. Zitterfreie Wärmebildung und Körpergrösse bei Säugetieren. Z vergl Physiol 1971;73:222-48.

43 Little RA. Heat production after injury. Br Med Bull 1985;41:226-31.

44 Stoner HB. An integrated neuro-endocrine response to injury. In: Wilkinson AW, Cuthbertson D, eds. Metabolism and the response to injury. Tunbridge Wells: Pitman Medical, 1976:194-201.

45 Krebs HA, Freedland RA, Hems R, Stubbs M. Inhibition of hepatic gluconeogenesis by ethanol. Biochem $J$ 1969;112:117-24.

46 Hadfield JM, Stoner HB. Interactions between ethanol and the responses to injury. $J$ Trauma 1983;23:518-22.

47 Sevitt S. The boundaries between physiology, pathology and irreversibility after injury. Lancet 1966;ii:1203-10.

48 Vitek V, Cowley RA. Blood lactate in the prognosis of various forms of shock. Ann Surg 1971;173:308-13.

49 Anderson CT, Westgard JO, Schlimgen K, Birbaum ML. Contribution of arterial blood lactate measurement to the care of critically ill patients. Am J Clin Pathol 1977;68:63-7.

50 Davies JWL. Physiological responses to burning injury. New York: Academic Press, 1982.

51 Frayn KN, Stoner HB, Barton RN, Heath DF, Galasko CSB. Persistence of high plasma glucose, insulin and cortisol concentrations in elderly patients with proximal femoral fractures. Age Ageing 1983;12:70-6.

52 Frayn KN, Price DA, Maycock PF, Carroll SM. Plasma somatomedin activity after injury in man and its relationship to other hormonal and metabolic changes. Clin Endocrinol 1984;20:179-87.

53 Frayn KN, Little RA, Stoner HB, Galasko CSB. Metabolic control in non-septic patients with musculoskeletal injuries. Injury 1984;16:73-9.

54 Black PR, Brooks DC, Bessey PQ, Wolfe RR, Wilmore DW. Mechanisms of insulin resistance following injury. Ann Surg 1982;196:420-35.

55 Ord MG, Stocken LA. Creatine and carbohydrate metabolism. Biochem J 1955;59:272-9.

56 Threlfall CJ, Stoner HB, Galasko CSB. Patterns in the excretion of muscle markers after trauma and orthopedic surgery. $J$ Trauma 1981;21:140-7.

57 Threlfall CJ, Maxwell AR, Stoner HB. Post-traumatic creatinuria. J Trauma 1984;24:516-23.

58 Baker SP, O'Neil B, Haddon W, Long WB. The injury severity score. A method for describing patients with multiple injuries and evaluating emergency care. J Trauma 1974;14:187-96.

59 Rennie MJ. Muscle protein turnover and the wasting due to injury and disease. Br Med Bull 1985;41:257-64.

60 Rennie MJ, Hundal HS, Babij P, et al. Characteristics of a glutamine carrier in skeletal muscle have important consequences for nitrogen loss in injury, infection and chronic disease. Lancet 1986;ii:1008-12.

61 Vinnars E, Bergström J, Fürst P. Influence of the postoperative state on the intracellular free amino acids in human muscle tissue. Ann Surg 1975;182:665-71.

62 Askanazi J, Carpentier YA, Michelsen CB, et al. Muscle and plasma amino acids following injury. Ann Surg 1980;190:78-85.

63 Milewski PJ, Threlfall CJ, Heath DF, Holbrook IB, Wilford K,
Irving MH. Intracellular free amino acids in undernourished patients with or without sepsis. Clin Sci 1982;62:83-91.

64 Newsholme EA, Crabtree B, Ardawi MSM. Glutamine metabolism in lymphocytes: its biochemical, physiological and clinical importance. $Q J$ Exp Physiol 1985;70:473-89.

65 Watters JM, Bessey PQ, Dinarello CA, Wolfe SM, Wilmore DW Induction of interleukin-1 in humans and its metabolic effects. Surgery 1985;98:298-306.

66 Clowes GHA, George BC, Villee CA, Saravis CA. Muscle proteolysis induced by a circulating peptide in patients with sepsis or trauma. N Engl J Med 1983;308:545-52.

67 Baracos V, Rodemann HP, Dinarello CA, Goldberg AL. Stimulation of muscle protein degradation and prostaglandin $E_{2}$ release by leukocyte pyrogen (interleukin-1). A mechanism for the increased degradation of muscle proteins during fever. N Engl J Med 1983;308:553-8.

68 Fleck A, Colley CM, Myers MA. Liver export proteins and trauma. Br Med Bull 1985;41:265-73.

69 Beisel WR. Sepsis and metabolism. In: Little RA, Frayn KN, eds. The scientific basis for the care of the critically ill. Manchester: Manchester University Press, 1986:103-22.

70 Askanazi J, Carpentier YA, Elwyn DH, et al. Influence of total parenteral nutrition on fuel utilisation in injury and sepsis. Ann Surg 1980;191:40-6.

71 Stoner HB, Little RA, Frayn KN, Elebute AE, Tresadern J, Gross E. The effect of sepsis on the oxidation of carbohydrate and fat. Br J Surg 1983;70:32-5.

72 Nanni G, Siegel JH, Coleman B, Fader P, Castiglione R. Increased lipid fuel dependence in the critically ill septic patient. J Trauma 1984;24:14-30.

73 Carpentier YA, Nordenström J, Robin A. Glycerol turnover and kinetics of exogenous fat in surgical patients. Acta Chir Scand 1981;(suppl)507:226-37.

74 Nordenström J, Carpentier YA, Askanazi J, et al. Free fatty acid mobilization and oxidation during total parenteral nutrition in trauma and infection. Ann Surg 1983;198:725-35.

75 White R, Frayn KN, Little RA, Threlfall CJ, Stoner HB, Irving $\mathrm{MH}$. Hormonal and metabolic responses to glucose infusion in sepsis studied using the hyperglycemic glucose clamp technique. JPEN 1987 (in press).

76 Sibbald WJ, Short A, Cohen MP, Wilson RF. Variations in adrenocortical responsiveness during severe bacterial infections. Ann Surg 1977;186:29-33.

77 Stoner HB, Little RA, Gross E, Milewski P. Metabolic complications of parenteral nutrition. Acta Chir Belg 1981;80:125-31.

78 Wilmore DW. The wound as an organ. In: Little RA, Frayn KN, eds. The scientific basis for the care of the critically ill. Manchester: Manchester University Press, 1986:45-59.

79 Henane R, Bittel J, Banssillon V. Partitional calorimetry measurements of energy exchanges in severely burned patients. Burns 1981;7:180-9.

80 Bessey PQ, Watters JM, Aoki TT, Wilmore DW. Combined hormonal infusion simulates the metabolic response to injury. Ann Surg 1984;200:264-81.

81 Gelfand RA, Matthews DE, Bier DM, Sherwin RS. Role of counterregulatory hormones in the metabolic response to stress. $J$ Clin Invest 1984;74:2238-48.

82 Bennett B, Towler HMA. Haemostatic response to trauma. $\mathrm{Br}$ Med Bull 1985;41:274-80.

83 McPhaden AR, Whaley $K$. The complement system in sepsis and trauma. Br Med Bull 1985;41:281-6.

Requests for reprints to: Professor HB Stoner, North Western Injury Research Centre, Stopford Building, University of Manchester, Oxford Road, Manchester M13 9PT, England. 